\title{
Synthesis, Characterization and Safety Assessment of Nano Selenium and Organic Selenium for Incorporation in Lamb Feed
}

\author{
S.S. Vajpeyee, J. Ramesh, R. Karunakaran, J. Muralidharan ${ }^{1}$, V. Sankar ${ }^{1}$
}

10.18805/ajdfr.DR-1695

\begin{abstract}
Background: Selenium is an important trace mineral required by the animals. It is an integral part of antioxidant system $\mathrm{p}_{1}$ protecting the body against free radical injury. Nano particles attract a widespread attention due to its high bioavailability and efficacy. The current study was aimed to synthesize, characterize nano selenium and evaluate the cytotoxic effect of nano selenium and organic selenium (selenocysteine) under in vitro condition in vero cell line.

Methods: Nano selenium was synthesized by wet chemical method by using sodium selenite, selenium powder, ascorbic acid and sodium hydroxide at laboratory level. In this study particle size, shape, zeta potential and selenium content were characterized by using Particle Size Analyser (PSA), Transmission Electron Microscope (TEM) and Inductively Coupled Plasma Mass Spectrometry (ICP-MS). The toxicity was analysed by MTT assay against vero cell line.

Result: The result revealed that selenium nano particles were spherical in shape, nano in size (less than $50 \mathrm{~nm}$ ) and pure in nature. The nano selenium and organic selenium (selenocysteine) effectively inhibited the growth of vero cells in a dose dependent manner.

Key words: Cell cytotoxicity, Nano selenium, Particle size, Zeta potential.
\end{abstract}

\section{INTRODUCTION}

Selenium is an essential trace element for animal health, immune function, productivity and reproductive performance in farm animals and found in both organic and inorganic forms in nature, has a specific place among the nutrients in animal feed because of its role in animal body (Mehdi and Dufrasne, 2016).

Nano mineral particles have a particle size in the range of 1-100 nm. At this scale, the physical, chemical and biological properties of materials differ fundamentally and often unexpectedly (Patil et al. 2012). The nano-sized particles are having higher potential than their conventional sources and would diminish the amount required (Sri Sindhura et al. 2014). Selenium nano-particles (Nano-Se), has novel characteristics such as high surface activity, great specific surface area, a lot of surface-active centres, strong adsorbing ability, high catalytic efficiency, high bioavailability and low toxicity (Skalickova et al. 2017).

Physical, chemical and biological methods can be used to produce nano selenium. The chemical method is the simplest and cost-effectivesince only a few chemicals can create nano minerals of uniform size in the laboratory (Lane et al. 2002). Hence, effective and controlled bulk production can be achieved by using the chemical methods. However, in chemical method there is always a chance of toxicity as hazardous chemicals are used during synthesis (Rajendran et al. 2013)

The chemical approach uses techniques such as chemical reduction, electrochemistry and photochemical reduction. It is reported that during synthesis process size, shape, stability and physiochemical properties of the nanoparticles are greatly influenced by variety of factors
Department of Animal Nutrition, Madras Veterinary College, Tamil Nadu Veterinary and Animal Science University, Chennai-600 007, Tamil Nadu, India.

${ }^{1}$ Mecheri Sheep Research Station, Pottaneri-636 453 Salem, Tamilnadu, India.

Corresponding Author: J. Ramesh, Department of Animal Nutrition, Madras Veterinary College, Tamil Nadu Veterinary and Animal Science University, Chennai-600 007, Tamil Nadu, India. Email: rameshnutrition@gmail.com

How to cite this article: Vajpeyee, S.S., Ramesh, J., Karunakaran, R., Muralidharan, J. and Sankar, V. (2021). Synthesis, Characterization and Safety Assessment of Nano Selenium and Organic Selenium for Incorporation in Lamb Feed. Asian Journal of Dairy and Food Research. DOI: 10.18805/ajdfr.DR-1695.

Submitted: 21-04-2021 Accepted: 02-07-2021 Online: 03-08-2021

viz temperature, concentration, reducing agent and stabilizing agent (Alexandridis, 2011). Thus, the synthesis and characterization of selenium nano particle is utmost importance.

Each type of nanoparticle has its own distinct physicochemical features such as particle size and surface area, their toxic effects exerted on the cells may also vary. Some of the toxic effects are irreversible and permanent, leading to cell deaths and some are reversible, after the exposures to nanoparticles are removed, and the cells may begin to proliferate normally (Hillegass et al. 2010). The mechanism of action that leads to the cell's deaths may also be different (Hillegass et al. 2010). Therefore, this experiment was proposed to synthesize, characterize and 
assess cytotoxicity of nano selenium for using it as a lamb feed supplement.

\section{MATERIALS AND METHODS Synthesis of selenium nano particles}

Nano particle of selenium was synthesized through chemical method. Nano selenium was synthesized by using two different methods and sources viz. sodium selenite and pure selenium powder from sigma at the Department of Animal Nutrition, Madras Veterinary College, Chennai during 2019. In the first method, nano selenium prepared by water phase solution method using selenium powder and sodium hydroxide as outlined by Kargar Razi etal. (2011) while in the second method, nano selenium was prepared using sodium selenite and ascorbic acid according to the modified method of Qian Le et al. (2010).

The yield of nano selenium was determined by weighing the product and comparing it to the precursors used. Organic selenium (selenocysteine) was purchased from sigma.

\section{Characterization of nano selenium}

When the particle size is reduced to nano size, the properties of the materials are likely to be far different from the bulk materials. In the present study, Transmission Electron Microscopy, Particle Size Analyzer, X Ray Diffractometer, Fourier Transform Infra-Red (FTIR) spectroscopy and Inductively Coupled Plasma Mass Spectrometry were used to analyze the properties like morphology, particle size distribution etc.

\section{In vitro Cytotoxicity Assay}

In vitro cytotoxicity assay was carried out in vero cell line (African green monkey kidney cell line) to ensure the safety of nano particle source of selenium as per the method of Mosmann, 1983. Serially diluted nano particles and organic selenium were incubated in ninety-six well plates containing vero cell line at the concentration of $10^{6}$ cells $/ \mathrm{ml}$ with solvent and medium following standard protocol. To this monolayer of cells in ninety-six well plates, serially diluted nano selenium was added and incubated for $24 \mathrm{hrs}$. The concentration selected were $0.25,0.5,1,2,5,10,20,30$, $40,50,60,70,80,90,100 \mu \mathrm{g} / \mathrm{ml}$. The different levels of selenium concentrations were selected based on the NRC (2007) recommendation. The samples were run in triplicates.
At the end of incubation, colorimetric method measured the reduction of yellow 3- (4, 5dimethythiazol-2-yl) -2, 5-diphenyl tetrazolium bromide (MTT) by mitochondrial succinate dehydrogenase of live cell. The parameters like per cent cell inhibition exhibited under different concentration of nano forms of selenium and organic selenium were studied. The per cent cell activity was determined by the following formula:

Cell viability $(\%)=(\mathrm{OD}$ of test cells/OD of control cells $) \times 100$.

\section{RESULTS AND DISCUSSION}

The product yield (recovery \%), particle size, zeta potential and selenium content in nano form of selenium are furnished in Table 1. The recovery percentage of nano particle source of selenium produced by chemical method using selenium powder as a precursor is $75.73 \%$ while yield from sodium selenite is $40.97 \%$. The result revealed that nano selenium derived from selenium powder contain $98.34 \%$ selenium whereas nano selenium derived from sodium selenite contain $97.62 \%$ selenium. The size assayed through both Transmission Electron Microscopy and particle size analyser, confirmed that the nano particle source of selenium produced was less than $50 \mathrm{~nm}$. The TEM image of produced nano selenium is presented in Fig 1 and Fig 2. Mean size assessed through Transmission Electron Microscopy is $43.46 \pm 2.31 \mathrm{~nm}$ and $21.6 \pm 2.11 \mathrm{~nm}$ for nano selenium derived from selenium powder and sodium selenite respectively. While mean size assessed through particle size analyser is $31.8 \pm 8.90 \mathrm{~nm}$ and $11.97 \pm 4.91 \mathrm{~nm}$ for nano selenium derived from selenium powder and sodium selenite respectively.

The X-Ray diffraction (XRD) pattern of synthesized nano selenium from both sources are presented in Fig 3 and Fig 4. $\mathrm{X}$-Ray diffraction pattern confirms that the synthesized nano particle source of selenium was free of impurities as it does not contain any characteristic XRD peaks other than selenium peak and the samples are nano in nature. The typical FTIR spectrum of synthesized nano particle source of selenium from selenium powder showed well-defined peaks at around $3853 \mathrm{~cm}^{-1}$ and $1163 \mathrm{~cm}^{-1}$ and FTIR spectrum of synthesized nano particle source of selenium from sodium selenite showed well-defined peaks at around $3864 \mathrm{~cm}^{-1}$ and $969 \mathrm{~cm}^{-1}$. The observed FTIR results confirmed that synthesized selenium nanoparticles were without any significant impurities. Zeta potential for nano selenium

Table 1: Product yield (recovery \%), particle size, zeta potential and selenium content in nano form of selenium (Mean \pm SE).

\begin{tabular}{lcr}
\hline \multirow{2}{*}{ Chemical name of source } & \multicolumn{2}{c}{ Characterization parameters } \\
\cline { 2 - 3 } & \multicolumn{1}{c}{ Selenium Powder } & Sodium selenite \\
\hline Recovery (\%) & $75.73 \pm 2.55$ & $40.97 \pm 0.79$ \\
Size (assessed through TEM) $\mathrm{nm}^{*}$ & $43.46 \pm 2.31$ & $21.6 \pm 2.11$ \\
Size (assessed through particle size analyser) $\mathrm{nm}^{*}$ & $31.8 \pm 8.90$ & $11.97 \pm 4.91$ \\
Zeta potential (mV)* & $-33.1 \pm 6.50$ & $-37.3 \pm 5.67$ \\
Selenium content $(\%)$ & $98.34 \pm 0.36$ & $97.62 \pm 0.14$ \\
Shape & Spherical & Spherical \\
\hline
\end{tabular}

${ }^{*}$ Mean of six observations. 
derived from selenium powder is $-33.1 \pm 6.5 \mathrm{mV}$ while from sodium selenite is $-37.3 \pm 5.67 \mathrm{mV}$ assessed through particle size analyser. Nanoparticles with zeta potential values greater than $+25 \mathrm{mV}$ or less than $-25 \mathrm{mV}$ typically have high degrees of stability. Dispersions with a low zeta potential value will eventually aggregate due to Van Der Waal interparticle attractions (Nanocomposix, 2012). Nano selenium particles produced in this study could be thus classified as having good stability.

Similar to our study Malhotra et al. (2016) prepared selenium nanoparticles by a wet chemical approach using ascorbic acid as a reducing agent and stabilized by coating with $10 \%$ dextrin with size of $64 \pm 0.158 \mathrm{~nm}$. Gangadoo et al. (2017) used solution phase synthesis approach for selenium nanoparticles by reducing selenium tetrachloride in the presence of ascorbic acid and recorded that nano selenium are $46 \mathrm{~nm}$ in size. Zhang et al. (2018) synthesized nano selenium with mean particle size of $36.8 \pm 4.1 \mathrm{~nm}$ using beta lactoglobulin as a stabilizer in redox system of ascorbic acid and selenite.

The selenium content of the produced nano particle sources of selenium were same as that of the original mega particle source from which they were produced. This indicates no loss in the selenium during the synthesis process. Kargar Razi et al. (2011) produced the sample with 99 percent selenium content in the nano sample. Concurring with this study, nano particles of selenium having similar size and shape were produced by other researchers.

Since every crystalline material has a special pattern of diffraction, the XRD technique can be used to identify crystalline structure of nanoparticles. The broadening of the peaks in XRD confirms the formation of particles in nano size (less than $50 \mathrm{~nm}$ ). If the nanoparticles are produced in an amorphous structure, no diffraction peak will be observed. Moreover, the smaller the nanoparticles are, the broader the XRD peaks appear (Noruzi, 2015). According to previous studies, the XRD spectrum of selenium nano particles usually have two strong and sharp reflection peaks at $2 \mathrm{~h}$ of $24^{\circ}$ and $30^{\circ}$ (Cai et al. 2018).

The functional group of synthesized Se nano particles were analysed by Fourier Transform Infra-Red (FTIR) spectroscopy, which showed chemical bonding in a target material. Kaviya et al. (2011) observed the shift in the absorption band after bio reduction at $1601 \mathrm{~cm}-1$ to 1584 $\mathrm{cm}^{-1}$ and indicated the formation of nanoparticles. The appearance of this peak was due to the presence of hydroxyl

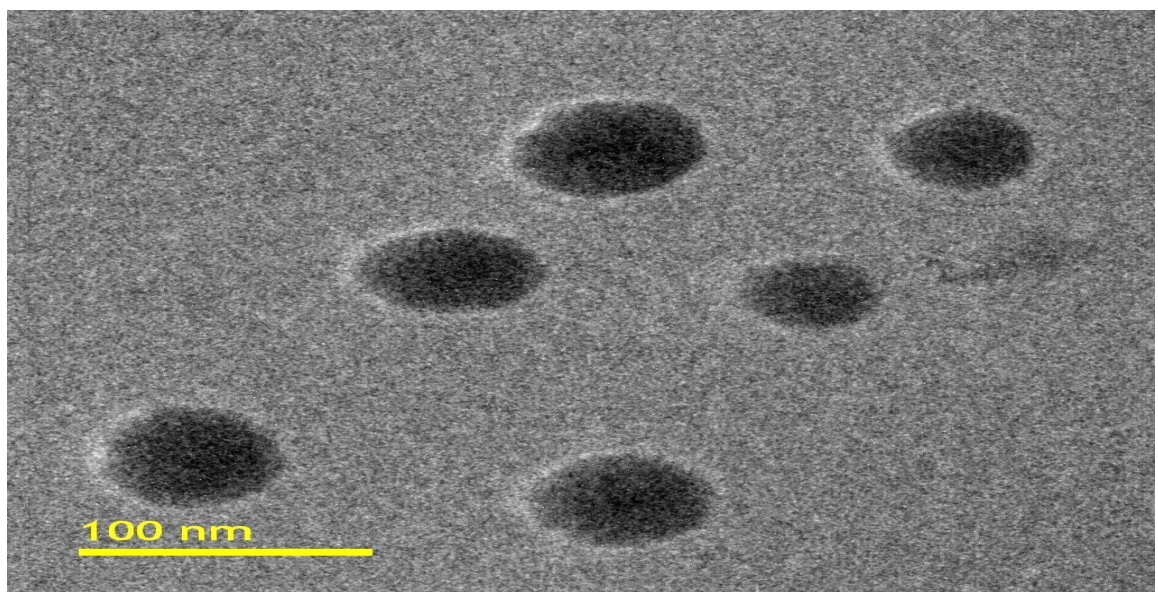

Fig 1: Transmission electron microscope image of nano selenium derived from selenium powder of size 40 to $50 \mathrm{~nm}$ and spherical in shape.

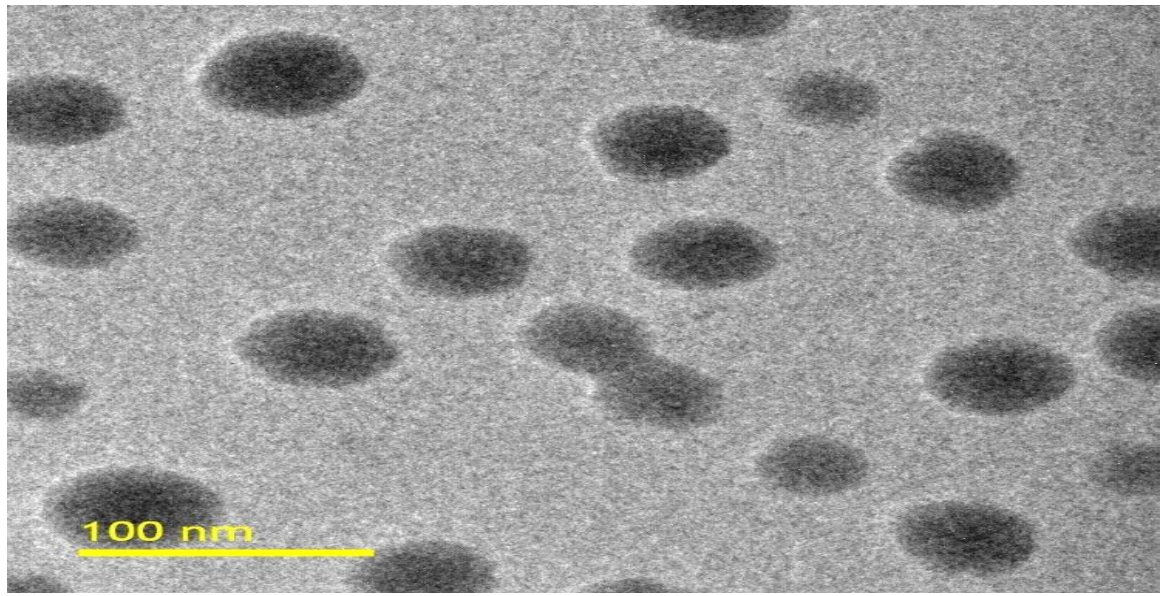

Fig 2: Transmission electron microscope image of nano selenium derived from sodium selenite of size 20 to $30 \mathrm{~nm}$ and spherical in shape. 


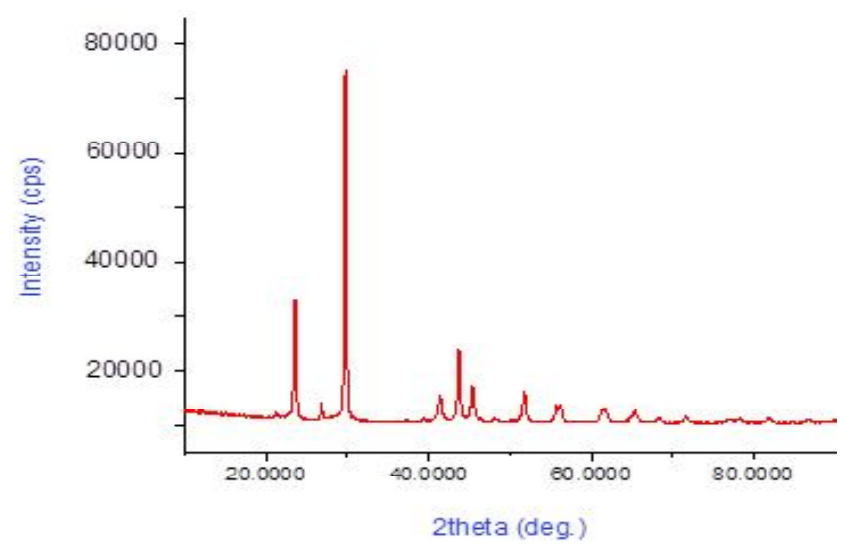

Fig 3: $\mathrm{X}$ ray diffraction pattern of nano selenium synthesized from selenium powder.

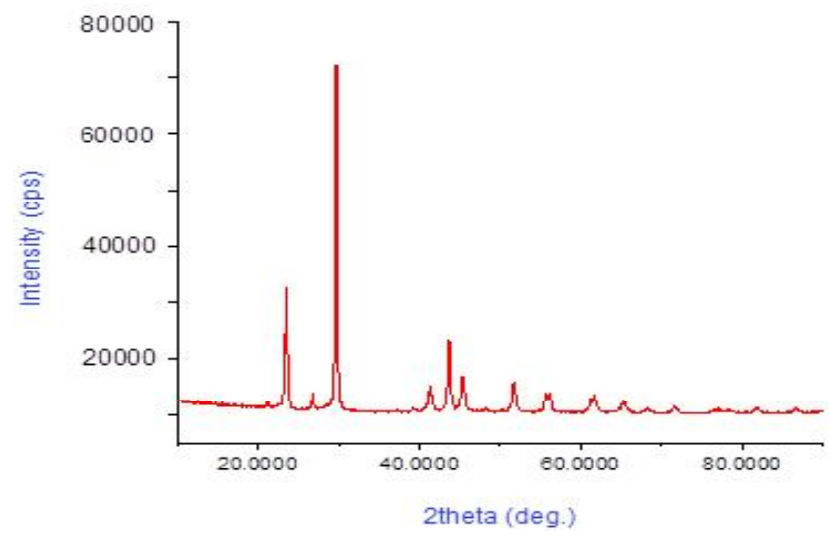

Fig 4: Xray diffraction pattern of nano selenium synthesized from sodium selenite. group stretching vibration of phenolic compounds which was responsible for the formation and stabilization of synthesized nanoparticles.

Rudakovskaya et al. (2014) showed that the spherical nano particles compared to rods had higher magnetic property and stability. Thus, the nano selenium synthesised in this study possessed this advantage.

\section{In vitro cytotoxicity study of nano selenium and organic selenium}

The per cent vero cell death for various concentrations of organic selenium particle and nano selenium (both) is presented in Table 2 and Fig 5. The cellular activities of cells exposed to test samples were also compared with the cell control. It shows the increased concentration of nano selenium would decrease the viability of cells which is indicated by round morphology of cells.

$\mathrm{IC}_{50}$ (Half Maximal Inhibitory Concentration) was calculated for nano selenium derived from both sources and organic selenium. The $I_{50}$ is defined as the sample concentration that is required to reduce the absorbance to half that of the control and which would give the $50 \%$ cell death. Based on the calculations, $I_{50}$ for nano selenium derived from selenium powder was $89.11 \mu \mathrm{g} / \mathrm{ml}$ while nano selenium derived from sodium selenite was $85.74 \mu \mathrm{g} / \mathrm{ml}$ and for organic selenium it was $86.77 \mu \mathrm{g} / \mathrm{ml}$. Since for nano selenium derived from both sources and organic selenium, $\mathrm{IC}_{50}$ value falls above $80 \mu \mathrm{g} / \mathrm{ml}$, it is concluded that there is no significant difference between $\mathrm{IC}_{50}$ values of nano selenium derived from both sources and organic selenium.

Alam et al. (2019) reported that $\mathrm{IC}_{50}$ value of selenium nanoparticles against $\mathrm{CHO}$ pro-cells was obtained to be 88

Table 2: Effect of different selenium sources on percentage cell viability of African Green Monkey Kidney (VERO) cell line determined by MTT assay (Mean \pm S.E.).

\begin{tabular}{lccc}
\hline Concentration, $\mu \mathrm{g} / \mathrm{ml}$ & Nano Selenium 1 & Nano Selenium 2 & Organic Selenium \\
\cline { 2 - 4 } & \% of cell viability & \% of cell viability & \% of cell viability \\
\hline 0.25 & $100.00 \pm 1.21$ & $99.96 \pm 0.07$ & $99.79 \pm 0.17$ \\
0.5 & $99.79 \pm 0.34$ & $99.87 \pm 0.04$ & $99.65 \pm 0.08$ \\
1 & $99.58 \pm 0.44$ & $99.06 \pm 1.44$ & $98.88 \pm 2.38$ \\
2 & $99.37 \pm 0.56$ & $98.20 \pm 1.11$ & $98.11 \pm 0.22$ \\
5 & $99.16 \pm 0.90$ & $91.41 \pm 0.32$ & $97.48 \pm 0.16$ \\
10 & $97.07 \pm 1.44$ & $89.69 \pm 2.11$ & $94.55 \pm 0.07$ \\
20 & $84.91 \pm 0.05$ & $89.57 \pm 0.33$ & $91.54 \pm 0.54$ \\
30 & $75.26 \pm 2.34$ & $78.79 \pm 1.88$ & $89.45 \pm 0.66$ \\
40 & $69.18 \pm 2.19$ & $75.72 \pm 1.34$ & $82.88 \pm 0.88$ \\
50 & $63.10 \pm 2.11$ & $74.78 \pm 0.13$ & $76.45 \pm 1.47$ \\
60 & $61.63 \pm 0.06$ & $69.09 \pm 1.12$ & $72.40 \pm 1.85$ \\
70 & $58.28 \pm 1.22$ & $62.12 \pm 0.43$ & $61.22 \pm 0.71$ \\
80 & $55.97 \pm 1.01$ & $52.71 \pm 1.13$ & $51.43 \pm 2.34$ \\
90 & $54.30 \pm 0.99$ & $42.84 \pm 1.81$ & $40.74 \pm 1.92$ \\
100 & $49.69 \pm 0.33$ & $40.44 \pm 1.53$ & $38.92 \pm 2.55$ \\
\hline
\end{tabular}

* Mean of three independent experiments.

Nano selenium 1 derived from sigma selenium powder.

Nano selenium 2 derived from sodium selenite. 


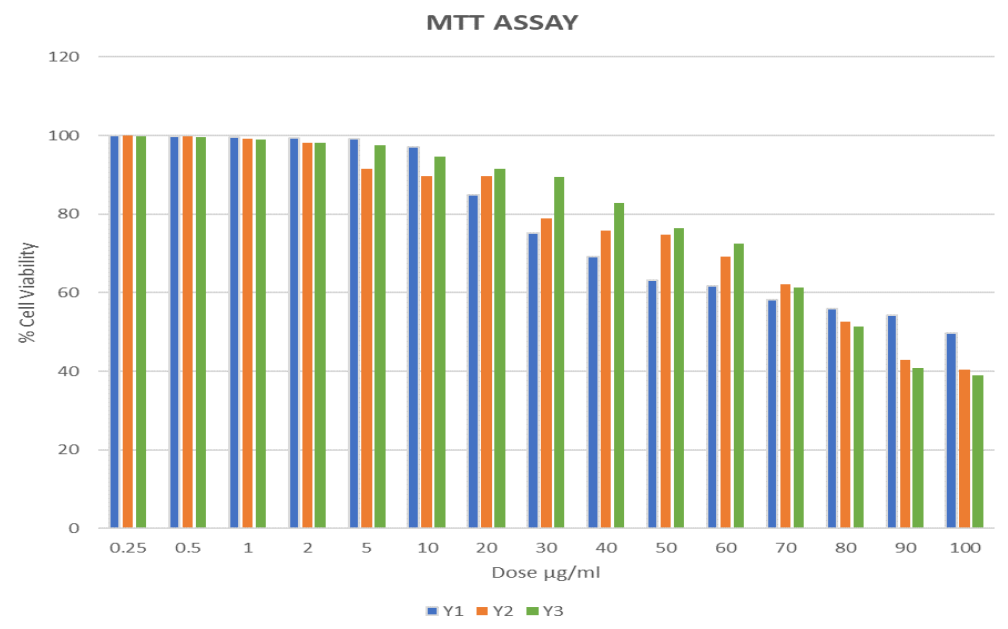

Fig 5: Viability of vero cells at different doses of different selenium sources.

Y1 (Blue bar) - Nano selenium derived from selenium powder.

Y 2 (Red bar) - Nano selenium derived from sodium selenite.

Y 3 (Green bar) - Organic selenium.

$\pm 2.1 \mu \mathrm{g} / \mathrm{ml}$. Salem et al. (2020) showed that IC-50 value of selenium nanoparticle against two different cell cultures, namely; human normal lung fibroblast (Wi 38) and human cancer colorectal adenocarcinoma epithelial (Caco-2) was 171.8 and $104.3 \mu \mathrm{g} / \mathrm{ml}$ respectively, data also proclaimed that the $\mathrm{IC}_{50}$ of Se-NPs for normal cell is higher than obtained from other cells. Hashem et al. (2021) showed that $\mathrm{IC}_{50}$ of mycosynthesized Se-NPs was $316.73 \mu \mathrm{g} / \mathrm{ml}$ towards Vero cell line CCL-81. Some reports declared that, Se-NPs showed lower cytotoxicity on normal cells compared with cancer cells (Vahidi et al. 2020).

Since, the synthesized nano-selenium had all the imperative characteristics of nano particles and our inclusion level of nano selenium in lamb feed is $0.3 \mathrm{mg} / \mathrm{kg}$ (NRC, 2007). Result of cell cytotoxicity assay moreover affirmed that both types of nano selenium and organic selenium (selenocysteine) are safe to use as lamb feed supplement and would replace its inorganic source to increase bioavailability and effectiveness.

\section{CONCLUSION}

Selenium nano particles would be successfully and effectively synthesized through wet chemical method from its precursor and the same could be characterized by several techniques as followed in this study for its quantity, size, shape, stability and purity.

The result of the present study showed that nanoselenium derived from both sources had all the characteristics of nano particle. Based on the result of in vitro cytotoxicity assay we would say that both type of nano selenium and organic selenium are nontoxic at our inclusion level. Hence, the synthesized selenium nano particles could be used as a feed supplement for lambs as per the standard recommended dosage $(0.3 \mathrm{mg} / \mathrm{kg}$ of feed). However, systematic and rigorous research must be performed to assess if there are any negative effects after feeding animals for a prolonged period of time.

\section{ACKNOWLEDGEMENT}

The authors are very much grateful to the authorities of Tamil Nadu Veterinary and Animal Sciences University Chennai for providing necessary facilities to carry out this research study.

\section{REFERENCES}

Alam, H., Khatoon, N. Raza, M. Ghosh, P.C. and Sardar, M. (2019). Synthesis and characterization of nano selenium using plant biomolecules and their potential applications. Bio Nanoscience. 9(1): 96-104.

Alexandridis, P. (2011). Gold nanoparticle synthesis, morphology control, and stabilization facilitated by functional polymers. Chemical Engineering and Technology. 34(1): 15-28.

Cai, W., Hu, T., Bakry, A.M., Zheng, Z., Xiao, Y. and Huang, Q. (2018). Effect of ultrasound on size, morphology, stability and antioxidant activity of selenium nanoparticles dispersed by a hyperbranched polysaccharide from Lignosusrhinocerotis. Ultrasonics Sonochemistry. 42: 823-31.

Gangadoo, S., Stanley, D., Hughes, R.J., Moore, R.J. and Chapman, J. (2017). The synthesis and characterisation of highly stable and reproducible selenium nanoparticles. Inorganic and Nano-Metal Chemistry. 47(11): 1568-1576.

Hashem, A.H., Khalil, A.M.A., Reyad, A.M. and Salem, S.S. (2021). Biomedical applications of mycosynthesizedselenium nanoparticles using penicillium expansum ATTC 36200. Biological Trace Element Research. 1: 11.

Hillegass, J.M., Shukla, A., MacPherson, M.B., Lathrop, S.A., Alexeeva, V., Perkins, T.N., Van der Vliet, A., Vacek, P.M., Gunter, M.E. and Mossman, B.T. (2010). Mechanisms of oxidative stress and alterations in gene expression by Libby six-mix in human mesothelial cells. Particle and fibre toxicology. 7: 1-15. 
Kargar Razi, M., Sarraf Maamoury, R. and Banihashemi, S. (2011). Preparation of nano selenium particles by water solution phase method from industrial dust. International Journal of Nano Dimension. 1(4): 261-267.

Kaviya, S., Santhanalakshmi, J. Viswanathan, B., Muthumary, J. and Srinivasan, K. (2011). Biosynthesis of silver nanoparticles using citrus sinensis peel extract and its antibacterial activity. Spectrochimica Acta, Part A. 79: 594-598.

Lane, R. Craig, B.and Babcock, W. (2002). Materials engineering with nature's building blocks. AMPTIAC Newsletter Spring.6: 31-37.

Malhotra, S., Welling, M.N., Mantri, S.B. and Desai, K. (2016). In vitro and in vivo antioxidant, cytotoxic and anti chronic inflammatory arthritic effect of selenium nanoparticles. Journal of Biomedical Materials Research Part B: Applied Biomaterials. 104(5): 993-1003.

Mehdi, Y. and Dufrasne, I. (2016). Selenium in cattle: A review. Molecules. 21: 545.

Mosmann, T. (1983). Rapid calorimetric assay for cellular growth and survival: Application to proliferation and cytotoxicity assays. Journal of Immunological Methods. 65: 55-63.

Nanocomposix, (2012). Zeta Potential Analysis of Nanoparticles. Nanocomposix.1(1): 1-6.

Noruzi, M. (2015). Biosynthesis of gold nanoparticles using plant extracts. Bioprocess and Biosystems Engineering. 38 (1):1-14 .

NRC (National Research Council), (2007). Nutrient Requirements of Small Ruminants: Sheep, Goats, Cervids and New World Camelids. The National Academies Press. Washington, DC (USA).

Patil, S.S., Kore, K.B. and Kumar, P. (2012). Nanotechnology and its applications in veterinary and animal science. Veterinary World. 2: 475-477.
Qian, Li., Chen, T. and Yang, F. (2010). Facile and controllable one step fabrication of selenium nano particles assisted by L- cysteine. Materials Letters. 64: 614 -617.

Rajendran, D.Thulasi, A.Jash, S.Selvaraju, S.and Rao, S.B.N. (2013). Synthesis and application of nano minerals in livestock industry.Animal Nutrition and Reproductive Physiology. 517-530.

Rudakovskya, C. and Karnik, H. (2014). Synthesis and characterization of Terpyridine tye Ligand protected gold coated $\mathrm{Fe} 3 \mathrm{O} 3$ nano particles. Mendeleev Communications. 20(3): 150160.

Salem, S.S., Fouda, M.M., Fouda, A., Awad, M.A., Al-Olayan, E.M., Allam, A.A. and Shaheen, T.I. (2020). Antibacterial, cytotoxicity and larvicidal activity of green synthesized selenium nanoparticles using Penicillium corylophilum. Journal of Cluster Science. 1: 11.

Skalickova, S., Baron, M. and Sochor, J. (2017). Nanoparticles biosynthesized by yeast: a review of their application. KvasnýPrůmysl. 63(6): 290-292.

Sri Sindhura, K., Selvam, P.P., Prasad, T.N.V. and Hussain, O.M. (2014). Synthesis, characterization and evaluation of effect of phytogenic zinc nanoparticles on soil exoenzymes. Applied Nanoscience. 4: 819-827.

Vahidi, H., Barabadi, H. and Saravanan, M. (2020). Emerging selenium nanoparticles to combat cancer: a systematic review. Journal of Cluster Science. 31(2): 301-309.

Zhang, W., Zhang, J., Ding, D., Zhang, L., Muehlmann, L.A., Deng, S.-E., Wang, X. Li, W. and Zhang, W. (2018). Synthesis and antioxidant properties of Lyciumbarbarum polysaccharides capped selenium nanoparticles using tea extract. Artificial Cells, Nanomedicine and Biotechnology. 46(7): 1463-70. 